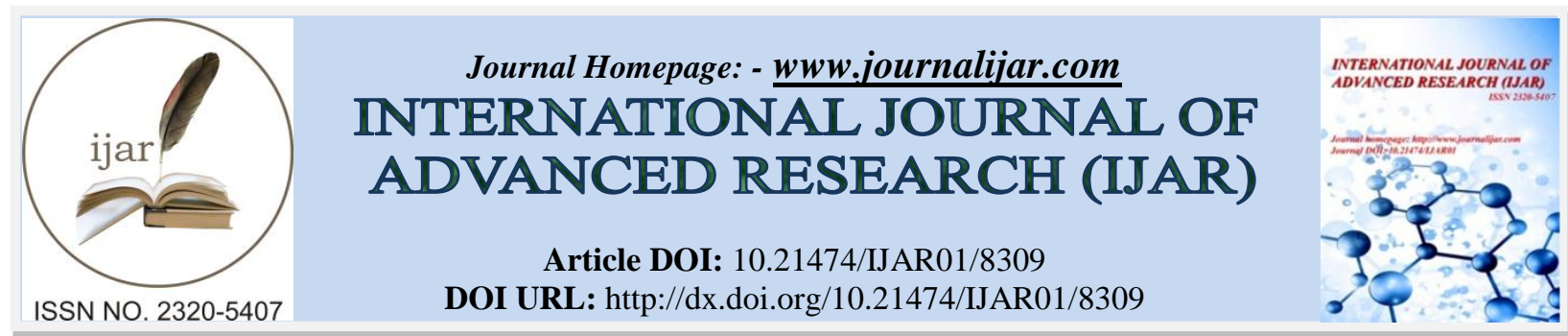

RESEARCH ARTICLE

\title{
SATISFACTION OF PATIENTS ADMITTED TO AL.IMAMAIN AL.KADHIMAIN TEACHING HOSPITAL WITH QUALITY OF HEALTH CARE SERVICES.
}

Berq J. Hadi Al-Yasseri.

Department of Family and Community Medicine, Al-Nahrain University/ College of Medicine, Baghdad, Iraq.

\section{Manuscript Info}

Manuscript History

Received: 04 November 2018

Final Accepted: 06 December 2018

Published: January 2019

Keywords:

Service quality, Patients' satisfaction, Servqual model.

\section{Abstract}

Introduction: In the modern open and multiple choices world, provision of high quality services and improvement of patients' conviction are becoming a critical objective to avoid patients' transfer to another health care provider. Thus, patients' satisfaction becomes crucial to the long-term success and profitability of health care organizations.

Objective: To explore satisfaction of patients with service quality in Al.Imamain Al.Kadimain teaching hospital by the use of serviqual model; and to identify factors that may influence this satisfaction, mainly patients' characteristics \& clinical setting.

Method: This is a cross-sectional study with an analytic element, carried out in Al.Imamain Al.Kadhimain teaching hospital, BaghdadIraq; during period of March through April, 2017. It involved patients admitted to internal medicine, gynecology, and surgery departments of hospital. The study relied on conducting face to face interviews using SERVQUAL questionnaire. This tool assessed service quality in five dimensions (tangibility, reliability, assistance, safety, and empathy).

Results: The study involved 400 patients. The majority of participants was women (61.0\%), young (57.8\%), housewives (56.0\%) and did not complete secondary education level $(\simeq 80 \%)$. The overall service quality score was $(4.237 \pm 0.649)$. The scores of various dimensions were: tangibility (3.751 \pm 0.709$)$, reliability $(4.386 \pm 0.775)$, assistance (4.348 \pm 0.810$)$, safety $(4.498 \pm 0.718)$ and empathy (4.204 \pm 0.850$)$. Factors found to be associated significantly with patients' satisfaction for services quality were education $(\mathrm{p}=0.003)$, occupation $(\mathrm{p}=0.004)$ and mode of admission to hospital ( $\mathrm{p}=0.022)$.

Conclusion: This study revealed that patients in Al.Imamain Al.Kadmain teaching hospital perceived service quality as satisfactory when estimated by SERVQUAL model. The dimensions which have relatively low scores are tangibility and empathy. Those patients who were satisfied with quality of health care services are more likely to advice other people to use hospital services.

Copy Right, IJAR, 2018,. All rights reserved.

Corresponding Author:-Berq J. Hadi Al-Yasseri.

Address:-Department of Family and Community Medicine, Al-Nahrain University/ College of Medicine, Baghdad, Iraq. 


\section{Introduction:-}

Health is a state of complete physical, mental and social well-being. Good health enables people to enjoy their life and have the chance to get what they want. The achievement and maintenance of this health status require the presence of proper and well-preserved healthcare services (1,2). In the modern open and multiple choices world, provision of high quality services and improvement of patients' conviction are becoming a critical objective to avoid patients' transfer to another health care provider. Thus, patients' satisfaction becomes crucial to the long-term success and profitability of health care organizations (3-5). Studies have shown that patients' behaviors (e.g. loyalty and trust) are affected greatly by the quality of healthcare they received (6). Satisfying the patients and taking their perceptions about service quality not only permits healthcare providers to identify the activities that require improvement, but also can save the hospitals' time and funds on resolving the patients' complaints (7).

Based on the above, it has become necessary that the patients feel that the care they receive in the hospital is coordinated, efficient, and guaranteed. Searching for a practical method for assessing these aspects in health facilities and particularly in hospitals has led to the development of several instruments to measure service quality. However, most of the authors pointed out that Servqual (Service Quality) questionnaire is the model with the most diffusion and application for this purpose (8). The servqual model investigates basically five dimensions in service quality (tangibility, reliability, responsiveness, assurance and empathy). It has been studied in many experimental studies in the hospital environment and its validity and reliability have been confirmed (9). As a result, Servqual has been used extensively for assessing quality service in different aspects of medical care (10).

The health situation in Iraq has undergone significant setbacks as a result of decades of wars, security conflicts and economic problems (11). In addition to these special circumstances, there are many other things which make the health status even worse. For example, poor standards of hygiene in many institutions have a considerable effect on the quality of care introduced. There are frequent complaints also of significant shortage in the delivered nursing services, sterilization methods and waste management (12).

In order to improve health situation in Iraq, hard work is required at all levels. A key step for the beginning is to know the weakness points; and there is no doubt that the patients are one of the most important elements in the diagnosis of these points. Nevertheless, there is limited information about patients' opinion with quality of health care services in Iraq; and there is no study using an approved validated method. Consequently, this study has been conducted to explore satisfaction of patients with quality of these services in Al.Imamain Al.Kadimain teaching hospital by the use of serviqual model; and to identify factors that may influence this satisfaction, mainly patients' characteristics \& clinical setting.

\section{Methods:- \\ Setting}

This is a cross-sectional study with an analytic element, carried out in Al.Imamain Al.Kadimain teaching hospital, Baghdad-Iraq; during period of March through April, 2017. It involved patients admitted to internal medicine, gynecology, and surgery departments of hospital during time of data collection. The study relied on conducting face to face interviews using paper-based, pre-validated (SERVIQUAL) questionnaire.

The sampling method was systematic random one, which involved all eligible patients in wards who accepted to participate. A sample size of 400 patients was chosen as it found to give $95 \%$ confidence level with less than $5 \%$ margin of error. To be included in the study, patient should be admitted for at least 24 hours before interview. Seriously ill patients for whom it would be difficult to reply, confused or cognitively impaired patients, and individuals less than 18 years were not included.

An informed verbal consent was obtained from all patients. A full explanation of the purposes and nature of the study was conveyed to them. The potential participants were clearly assured that their participation is voluntary and any data obtained would be treated confidentially and for the purpose of the research only.

\section{Study Instrument}

The Serviqual scale questionnaire which was used previously in many similar studies (13-18) was adapted for evaluating patients' satisfaction with service quality. It was translated to Arabic to make it more suitable for local circumstances of current study. The study tool was pre-tested on a sample of 30 patients, selected randomly to know 
the time needed to fill it, figure out any difficult, sensitive, unclear, or unneeded questions, and make it more suitable for patients in our community. Minor changes were made on original version after conducting this pilot study. Nevertheless, these changes did not cause significant difference in content of original questionnaire which may affect its validity.

The study tool consisted of two main sections. The First section contained set of questions gathering information about socio-demographic characteristics of respondents (e.g. gender, age, educational level, and current occupation); their clinical setting (i.e. way of admission, self-rated health status and history of hospital admission in last 5 years); and whether s/he will advise others to attend this hospital. The second section contained 21 items assessing opinion to the 5 dimensions of Servqual scale (tangibility - 5 items, reliability - 5 items, assistance - 4 items, safety - 3 items, empathy - 4 items). Response to each question was scored using a Likert-type scale 5-point method: 1 was very dissatisfied, 2 was not satisfied, 3 was neutral, 4 was satisfied, and 5 was very satisfied. Detailed description of the five dimensions is clarified below:

1. Tangibility: inquires about physical facilities, equipment, and appearance of employees in organization;

2. Reliability: manages the ability to provide secure and reliable services so that the customers' expectations are met;

3. Responsiveness: evaluates the willingness to serve and support customers and deliver prompt service;

4. Assurance: represents the competence and ability of employees to induce a sense of trust and confidence in the client;

5. Empathy: assesses how much an organization could provide an individualized care, empathy and personal attention to its customers.

\section{Statistical Analysis:-}

The SPSS software program, version 22, was used for all computerized statistical analyses. The results were expressed as mean \pm SD (standard deviation), or as frequency \& percentage. Variables were compared by using $t$ test or by analysis of variance (ANOVA) test. $P$ - value equal or less than 0.05 was considered to be statistically significant.

\section{Results:-}

This study involved 400 patients admitted to different departments of Al.Imamain Al.Khadimain teaching hospital. All participants were presented in the hospital wards at the time of interview. The distribution of the study sample according to their sociodemographic and health-related characteristics is shown in Table1. The majority of patients were young $(57.8 \%)$ with age between 18 and 39 years; and there were almost equal proportions of patients distributed among middle age (40-59 years) and old age (60 years and more) groups. More than $60 \%$ of respondents were women; and in consistency, the largest proportion of respondents was housewives (56.0\%). In regard to the education status, around $80 \%$ of patients did not complete secondary education level.

Concerning the health status of patients (self-rated) at the moment of filling the questionnaire; most of them had good or very good health, nearly one-third were with fair health, and only $7.5 \%$ had poor health status. Screening the way of admission revealed that the largest proportion of respondents (56.5\%) were admitted by specialists doctors and about one-third were admitted through emergency unit, and the remaining (8.2\%) were admitted through other ways (e.g. admission through general practitioner in primary health care centers and transfer from another hospital). Inquiring about history of hospital admission in the last 5 years revealed that more than half of patients have at least one previous admission. When patients were asked if they will advise others to come to this hospital, the vast majority answered "yes" (81.3\%).

Table 2 displays the perceived scores of the members of the study for the service quality provided in Al.Imamain Al.Kadhimain teaching hospital in the five dimensions of Servqual scale. In general, the perception of participants was high in all dimensions. The safety took the first rank with an average of (4.498 \pm 0.7181$)$; in the second place there was reliability with an average of $(4.386 \pm 0.7747)$. In the third place, the assistance was present with an average of (4.348 \pm 0.8103$)$. The empathy dimension came before the last with an average of (4.204 \pm 0.8496$)$, and in the last place came the tangibility dimension with an average of $(3.751 \pm 0.7094)$. The perceived score for service quality is the mean of the five dimensions mentioned above. Its amount was (4.237 \pm 0.649$)$. 
Table1:-Baseline characteristics of participants

\begin{tabular}{|c|c|}
\hline Character & Value (\%) \\
\hline Total Number & $400(100.0 \%)$ \\
\hline \multicolumn{2}{|l|}{ Age group } \\
\hline - Young age & $231(57.8 \%)$ \\
\hline - Middle age & $86(21.5 \%)$ \\
\hline - Old age & $83(20.7 \%)$ \\
\hline Women Gender & $244(61.0 \%)$ \\
\hline \multicolumn{2}{|l|}{ Years of Education } \\
\hline$<6 \mathrm{yr}$. & $135(33.8 \%)$ \\
\hline $6-11 \mathrm{yr}$. & $180(45.0 \%)$ \\
\hline$\geq 12 \mathrm{yr}$ & $85(21.2 \%)$ \\
\hline \multicolumn{2}{|l|}{ Occupation } \\
\hline - Housewives & $224(56.0 \%)$ \\
\hline - Employees/ workers & $123(30.8 \%)$ \\
\hline - No work & $38(9.5 \%)$ \\
\hline - Students & $15(3.7 \%)$ \\
\hline \multicolumn{2}{|l|}{ Self-Rated Health } \\
\hline - Very good & $34(8.5 \%)$ \\
\hline - Good & $211(52.8 \%)$ \\
\hline - Fair & $125(31.3 \%)$ \\
\hline - Poor & $30(7.5 \%)$ \\
\hline \multicolumn{2}{|l|}{ Mode of Admission } \\
\hline - Specialist doctor & $226(56.5 \%)$ \\
\hline - Emergency unit & $141(35.3 \%)$ \\
\hline - Others ${ }^{*}$ & $33(8.2 \%)$ \\
\hline $\begin{array}{l}\text { Have you ever been admitted to a hospital in the last } 5 \text { years? } \\
(Y e s)\end{array}$ & $235(58.8 \%)$ \\
\hline Do you advise others to come to this hospital? (Yes) & $325(81.3 \%)$ \\
\hline
\end{tabular}

* Others mean admission through general practitioner and transfer from another hospital

Table2:-Patient's perceived scores for service quality

\begin{tabular}{|c|c|c|}
\hline Dimension & Score mean & SD \\
\hline Tangibility & 3.751 & 0.710 \\
\hline Reliability & 4.386 & 0.775 \\
\hline Assistance & 4.348 & 0.810 \\
\hline Safety & 4.498 & 0.718 \\
\hline Empathy & 4.204 & 0.850 \\
\hline Service Quality & $\mathbf{4 . 2 3 7}$ & $\mathbf{0 . 6 4 9}$ \\
\hline
\end{tabular}

The relationship between patients' satisfaction with service quality and sociodemographic characteristics of patients is illustrated in Table3. The results showed that no significant difference was noticed regarding assessment of service quality among the different age groups $(p=0.338)$ and between both genders $(p=0.127)$. On the other hand, there was statistically significant association between patients' satisfaction and social factors like education $(p$ $=0.006)$ and occupation $(p=0.004)$. Post-hoc analysis revealed that participants with at least secondary educational level have significantly lower satisfaction score than those with only primary or less education. In the same context, those without work have significantly lower satisfaction than housewives, workers and employees.

Regarding relationship between patients' satisfaction with service quality and factors related to clinical status and admission, Table4 is designed to demonstrate the findings. The established analysis revealed that there was statistically significant association between satisfaction with service quality and mode of admission to hospital $(p=0.022)$. Those who have been admitted by specialists possessed significantly higher satisfaction score than those who admitted through general practitioner in primary health care centers and those who transferred from another hospital. The patients who will advise other patients to use this hospital services carried highly significant better 
satisfaction than others $(p<0.001)$. The self-rated health status and history of previous admission in past five years did not show significant relationship with satisfaction score.

Table3:-Relationship between patients' satisfaction with service quality and sociodemographic characteristics of them

\begin{tabular}{|c|c|c|c|}
\hline \multicolumn{2}{|c|}{ Character } & Score; mean (SD) & $P$-value \\
\hline \multirow{3}{*}{ Age } & Young age & $4.24(0.67)$ & \multirow{3}{*}{0.338} \\
\hline & Middle age & $4.31(0.55)$ & \\
\hline & Old age & $4.19(0.68)$ & \\
\hline \multirow{2}{*}{ Gender } & Men & $4.18(0.64)$ & \multirow{2}{*}{0.127} \\
\hline & Women & $4.28(0.66)$ & \\
\hline \multirow{3}{*}{ Education } & $<6 \mathrm{yr}$. & $4.33(0.65)$ & \multirow{3}{*}{0.003} \\
\hline & $6-11 \mathrm{yr}$. & $4.26(0.59)$ & \\
\hline & $\geq 12 \mathrm{yr}$. & $4.03(0.72)$ & \\
\hline \multirow{4}{*}{ Occupation } & Housewife & $4.30(0.63)$ & \multirow{4}{*}{0.004} \\
\hline & Employed/ worked & $4.24(0.62)$ & \\
\hline & No work & $3.90(0.74)$ & \\
\hline & Student & $4.14(0.65)$ & \\
\hline
\end{tabular}

Table4:-Relationship between patients' satisfaction with Service Quality and Clinical setting of them

\begin{tabular}{|c|c|c|c|}
\hline \multicolumn{2}{|c|}{ Character } & Score; mean (SD) & $P$-value \\
\hline \multirow{4}{*}{ Self-Rated Health } & Very good & $4.29(0.70)$ & \multirow{4}{*}{0.517} \\
\hline & Good & $4.22(0.67)$ & \\
\hline & Fair & $4.29(0.60)$ & \\
\hline & poor & $4.11(0.64)$ & \\
\hline \multirow{3}{*}{ Mode of Admission } & Specialist doctor & $4.30(0.62)$ & \multirow{3}{*}{0.022} \\
\hline & Emergency unit & $4.20(0.65)$ & \\
\hline & Others & $4.00(0.71)$ & \\
\hline \multirow{2}{*}{$\begin{array}{l}\text { Hospital Admission in } \\
\text { past } 5 \text { years }\end{array}$} & Yes & $4.21(0.65)$ & \multirow{2}{*}{0.338} \\
\hline & No & $4.28(0.65)$ & \\
\hline \multirow{2}{*}{ Advice to Use Hospital } & Yes & $4.35(0.55)$ & \multirow{2}{*}{$<0.001$} \\
\hline & $\mathrm{No} / \mathrm{DNK}$ & $3.73(0.82)$ & \\
\hline
\end{tabular}

\section{Discussion:-}

Understanding health care consumers' perceptions is highly essential and relevant if an organization wants to survive. It may bring also a new vision to improve the quality of health care. The findings of this study reveal that patients' general perceptions for the quality of the services provided in Al.Imamain Al.Kadmain teaching hospital were satisfactory. However, certain issues and challenges have been identified with more detailed analysis of the dimensions making up the Serviqual questionnaire.

The present result of overall satisfaction with service quality is equal or even better than that reported in previous studies. A study conducted by Ajarmah et al (13) in Jordanian hospitals estimated perceived service quality as measured by mean servqual score between (3.4025) \& (3.7267). Another study conducted by Peprah et al in Ghana (14) found that majority of respondents rating the services as good or high when asked through direct question about their opinion. The result of our study indicated the success of the health services providers in achieving the performance criteria set at a high level in spite of all difficulties facing health sector in Iraq.

When it comes to satisfaction with specific dimensions of score, the largest defect in current study appeared in tangibility, followed by empathy, assistance, reliability, and assurance. The management of these points gives the opportunity for further improvements in services. On revision of previous studies, results appear to be varied across content. For instance, A study performed by Suifan (15) on Iraqis attended Jordan red crescent health centers found that the highest quality dimensions concern for them were tangibles, followed by assurance, responsiveness, and lastly empathy as that study did not involve reliability dimension. 
Lam (16) applied the Servqual scale in a hospital in Hong Kong. It was concluded that the highest defect in score was registered by the empathy dimension, followed by responsiveness, assurance and reliability. Furthermore, Lim and Tang (17) applied the Servqual scale in a hospital located in Singapore and concluded that responsiveness was the dimension that had the highest defect, followed by assurance and reliability. In Romania, Purcarea et al (18) found that tangibles dimension turned out to have the highest gap score, followed by responsiveness and reliability.

The patients in present study are least pleased with tangible elements (mainly equipment status, cleanliness of physical facilities and availability of drugs and required medical items). This indicates that level of parameters of this items were less than patients' expectation. This may be attributed to deficiency in financial allocations and low spending on the health sector due to economic crisis the country faced at the time of study. It makes the official bodies unable to provide complete support to the needs of public hospitals. Many previous studies declared the dependence of perceived quality of services on tangibility dimension. Results reported by Parasuraman and Zeithaml (19) and Boshoff and Gray (20) stated that patients' perceptions of service quality were mainly affected by environment and physical evidence than the core services. Sohail (21) also emphasized in his study the importance of modern equipment, cleanliness, and visual conditions of facilities.

The other dimension in scale which reported relatively low score is empathy; especially for the items of taking care to patients' specific needs \& their believes. This may be due to the work overload and lack of adequate staff number which prevent proper communication with patients and leading to shortening in the awareness of patients need. Nevertheless, these reasons should not be an excuse and justification for lack of proper communication with patients and listening to their problems. Tam(22) found that longer consultations enable opportunities for effective communication which consequently lead to better medical care and higher patient satisfaction.

\section{Analyses of relationship between patient's characteristics and satisfaction with service quality}

Concerning sociodemographic factors, the first feature that can be noted is the lower level of satisfaction in those with secondary degree of education or higher. This may be explained as those people had enough knowledge and judgment so that they no longer feel confused about the situations they face. Therefore, it is easy for them to discover problems when they receive medical treatment, which leads to lower perception of satisfaction. The second feature is that those without work and retired individuals had also lower satisfaction than others. This can be attributed to the state of unemployment that those individuals suffered. This state affects their psychological state and makes their view negative of all things in life. The demographic factors did not show significant association in this study, No significant differences were noticed regarding assessment of service quality among those of different ages or sex.

Socio-demographic and individual variables are known to show positive association with patient satisfaction. However, results are inconsistent and sometimes contradictory indicating the effects of specific conditions and circumstance related to each study. In Greece, Priporas et al. (23) found that males and young patients tend to rate satisfaction a little higher than females and older patients. Another study conducted in Jordan by Alrubaiee et al (24) concluded that older patients, women, and patients with higher education tended to report higher levels of healthcare quality. Mummalaneni and Gopalakrishna, (25) found that only income was the influenced patient satisfaction. Lastly, Mohebifar et al (26) study in Iran did not report any significant difference of age, sex and education on perceived patients' satisfaction with quality of care services.

Among factors that expressed significant relation with satisfaction in present study was mode of admission. Those who were admitted by specialist doctors to hospital or through doctors in emergency unit showed higher rate of satisfaction than others which referred from general practice or other hospitals. This indicates that patients who came directly to hospital appreciated its services more than those transferred from other health facilities. Other clinical factors like self-rated health situation \& history of attending hospital in last 5 years did not reveal significance. There was no much studies explored these clinical factors. However, Alrubaiee et al (24) reported that patients with better health have higher satisfaction with quality of health care services. Mečev et al (27) found marginal association in primary health care sector in Croatia between satisfaction \& service usage frequency as those who used services frequently were more satisfied than those who use them less than once a year.

\section{Limitations and strengths}

The important strength of this study is its originality. Up to our knowledge, this study is the first in Iraq that aims to assess the patients' satisfaction with quality of health services in teaching hospital, in a country facing financial 
constrains affecting allocation and resources to health. However, results of this study should be viewed in the light of the study's limitations. First, they cannot be generalized on all hospital departments, since the research was primarily oriented towards services provided in inpatient wards; excluding in this way outpatient department, emergency services, and dental clinics which certainly have a clear role on patients' opinion in determining the selected hospital. Second, the research was performed in teaching public hospital; therefore, the findings cannot be concluded for other hospital types. Ultimately, the study did not include important groups of patients like children, psychiatric patients and those who were unconscious or unable to communicate. These groups need special maneuvers to evaluate the perception of persons responsible on them.

\section{Conclusions:-}

This study revealed that patients in Al.Imamain Al.Kadmain teaching hospital perceived service quality as satisfactory when estimated by servqual model. The dimensions which have relatively low scores are tangibility and empathy. Those patients who were satisfied with quality of health care services are more likely to advice other people to use hospital services. Sociodemographic predictors of satisfaction in the present study were education and occupational status. Age and gender did not generate significant differences in the perception of service quality. Mode of admission to hospital appeared to be associated significantly with perceived satisfaction for quality of health care services; while health status of patients and frequency of admission did not reveal significance.

This study explores an important and sensitive area in health administration. Its results should be noted by policy makers and hospital managers as a signal to improve the perceived healthcare quality of services or lose patients to competitors, whether they are local or foreign entities.

\section{References:-}

1. Elliot D. Defining the relationship between health and well-being in bioethics. The New Bioethics. 2016;22(1):4-17.

2. Pillai KR, Kumari A. Patients' perception on service quality of hospital. International Journal of Management and Applied Science. 2016;2(5):80-84.

3. Ramsaran-Fowdar RR. The relative importance of service dimensions in a healthcare setting. Int J Health Care Qual Assur. 2008;21(1):104-24.

4. Salmond SW, Echevarria M. Healthcare transformation and changing roles for nursing. Orthop Nurs. 2017;36(1):12-25..

5. Rice T. The behavioral economics of health and health care. Annu Rev Public Health. 2013;34:431-47..

6. Andaleeb SS. Service quality perceptions and patient satisfaction: a study of hospitals in a developing country. Social Science \& Medicine. 2001;52(9):1359-70.

7. Pakdil F, Harwood TN. Patient satisfaction in a preoperative assessment clinic: an analysis using SERVQUAL dimensions. Total Quality Management \& Business Excellence. 2005;16(1):15-30.

8. Akhade GN, Jaju SB, Lakhe RR. Healthcare service quality dimensions in various countries. IOSR Journal of Nursing and Health Science. 2016; 5(3):70-76.

9. Amjeriya D , Malviya RK. Measurement of service quality in healthcare organization. International Journal of Engineering Research \& Technology. 2012;1(8):1-18.

10. Rashid WE, Jusoff HK. Service quality in health care setting. Int J Health Care Qual Assur. 2009;22(5):471-82.

11. Izard M. Iraq: putting the health-care system back on its feet [Internet]. International Committee of Red Cross. Updated on 29-07-2010 [cited 22 April 2017]. https://www.icrc.org/eng/resources/documents/update/iraqupdate-290710.htm.

12. Tirman J. How Will We Remember Operation Iraqi Freedom? [Internet]. Washington Spectator 2011. Published on 15-11-2011 [cited 10 December 2018]. https://washingtonspectator.org/how-will-we-rememberoperation-iraqi-freedom.

13. BS Ajarmah, TN Hashem. Patient satisfaction evaluation on hospitals; comparison study between accredited and non-accredited hospitals in Jordan. European Scientific Journal. 2015;11(32):298 - 314.

14. Peprah AA, Atarah BA. Assessing patient's satisfaction using SERVQUAL model: A case of sunyani regional hospital, Ghana. International Journal of Business and Social Research (IJBSR). 2014; 4(2): 133 - 143.

15. Suifan TS. Quality of health services provided to Iraqis at Jordan red crescent health centers. American Journal of Economics and Business Administration. 2010; 2 (1): 35-43

16. Lam SSK. Servqual: A tool for measuring patients' opinion of hospital service quality in Hong Kong. Total Quality Management. 1997; 8(4): 53-71. 
17. Lim PC, Tang NKH. A study of patients' expectation and satisfaction in Singapore hospitals. International Journal of Health Care Quality Assurance. 2000; 13: 290-299.

18. Purcarea VL, Gheorghea IR, Petrescub CM. The assessment of perceived service quality of public health care services in Romania using the SERVQUAL scale. Procedia Economics and Finance. 2013; 6: 573 - 585.

19. Parasuraman AVA, Zeithaml LL. A conceptual model of service quality and its implications for future research. J Marketing. 1985;49:41-50.

20. Boshoff C, Gray B. The relationship between service quality, customer satisfaction and buying intentions in the private hospital industry. S Afr J Bus Manag. 2004; 35(4):27-37.

21. Sohail SM. Service quality in hospitals: more favorable than you might think. Manag Serv Qual. 2003;13(3):197-206.

22. Tam J. "Linking quality improvement with patient satisfaction: a study of a health service centre". Marketing Intelligence \& Planning. 2007; 25(7): 732- 745.

23. Priporas C, Laspa C, Kamenidou I. Patient satisfaction measurement for in-hospital services :A pilot study in Greece. Journal of Medical Marketing. 2008; 8(4): 325-340.

24. Alrubaiee L, Alkaa'ida F. The Mediating Effect of Patient Satisfaction in the Patients' Perceptions of Healthcare Quality - Patient Trust Relationship. International Journal of Marketing Studies. 2011; 3(1): 103 - 127.

25. Mummalaneni V, Gopalakrishna P. Mediators vs. Moderators of patient satisfaction. Journal of Health Care Marketing. 1995; 15(4): 16-22.

26. Mohebifar R, Hasani H, Barikani A, Rafie S. Evaluating service quality from patients' perceptions: Application of importance - performance analysis method. Osong Public Health Res Perspect. 2016; 7(4):233-8.

27. Mečev D, Goleš IK. Primary healthcare service quality measurement: SERVIQUAL scale. Ekonomski Vjesnik/ Econviews. 2015: 1: 161-177.

Annex 1:-SERVIQUAL Scale Questionnaire

\begin{tabular}{|c|c|c|c|c|c|}
\hline Dimensions and items & $\begin{array}{l}\text { Strongly } \\
\text { Disagree }\end{array}$ & Disagree & Uncertain & Agree & $\begin{array}{l}\text { Strongly } \\
\text { Agree }\end{array}$ \\
\hline \multicolumn{6}{|l|}{ Tangibility } \\
\hline 1. The hospital has preserved and modern equipment & 1 & 2 & 3 & 4 & 5 \\
\hline $\begin{array}{l}\text { 2. The hospital's physical facilities is visually } \\
\text { appealing and pleasant }\end{array}$ & 1 & 2 & 3 & 4 & 5 \\
\hline $\begin{array}{l}\text { 3. The hospital staff have neat appearance and outfit } \\
\text { in accordance with properties of work } \\
\text { environment }\end{array}$ & 1 & 2 & 3 & 4 & 5 \\
\hline $\begin{array}{l}\text { 4. The reports and other documents delivered to the } \\
\text { patient is easily understood and visually } \\
\text { appealing }\end{array}$ & 1 & 2 & 3 & 4 & 5 \\
\hline $\begin{array}{l}\text { 5. Essential medicines and medical supplies are } \\
\text { available in the hospital }\end{array}$ & 1 & 2 & 3 & 4 & 5 \\
\hline \multicolumn{6}{|l|}{ Reliability } \\
\hline $\begin{array}{l}\text { 6. The hospital conducts its essential activities at all } \\
\text { times }\end{array}$ & 1 & 2 & 3 & 4 & 5 \\
\hline $\begin{array}{l}\text { 7. The hospital demonstrates sincere interest in } \\
\text { solving the problems of the patient }\end{array}$ & 1 & 2 & 3 & 4 & 5 \\
\hline $\begin{array}{l}\text { 8. The hospital performs the services \& procedures } \\
\text { correctly from the first time, not causing rework }\end{array}$ & 1 & 2 & 3 & 4 & 5 \\
\hline $\begin{array}{l}\text { 9. The hospital provides its services within the } \\
\text { promised implementation time }\end{array}$ & 1 & 2 & 3 & 4 & 5 \\
\hline $\begin{array}{l}\text { 10. The hospital submits reports, documents and } \\
\text { information about the patient without errors }\end{array}$ & 1 & 2 & 3 & 4 & 5 \\
\hline \multicolumn{6}{|l|}{ Assistance } \\
\hline $\begin{array}{l}\text { 11. The staff inform patients exactly when services } \\
\text { will run }\end{array}$ & 1 & 2 & 3 & 4 & 5 \\
\hline $\begin{array}{l}\text { 12. The hospital staff are available to respond to the } \\
\text { requests of the patient at all times }\end{array}$ & 1 & 2 & 3 & 4 & 5 \\
\hline 13. The staff work to help the patients \& respond to & 1 & 2 & 3 & 4 & 5 \\
\hline
\end{tabular}




\begin{tabular}{|c|c|c|c|c|c|}
\hline their inquiries & & & & & \\
\hline 14. The staff meet promptly the patients need & 1 & 2 & 3 & 4 & 5 \\
\hline \multicolumn{6}{|l|}{ Safety } \\
\hline $\begin{array}{l}\text { 15. The behavior of the staff reassure patients and } \\
\text { make them comfortable }\end{array}$ & 1 & 2 & 3 & 4 & 5 \\
\hline 16. The staff are polite and courteous to the patients & 1 & 2 & 3 & 4 & 5 \\
\hline $\begin{array}{l}\text { 17. The work team in hospital have adequate } \\
\text { knowledge to answer questions of patients }\end{array}$ & 1 & 2 & 3 & 4 & 5 \\
\hline \multicolumn{6}{|l|}{ Empathy } \\
\hline 18. The staff pay individual attention to each patient & 1 & 2 & 3 & 4 & 5 \\
\hline $\begin{array}{l}\text { 19. The hospital operates at times suitable to the } \\
\text { patients }\end{array}$ & 1 & 2 & 3 & 4 & 5 \\
\hline $\begin{array}{l}\text { 20. The hospital staff give personal attention to the } \\
\text { patient's beliefs and emotions }\end{array}$ & 1 & 2 & 3 & 4 & 5 \\
\hline 21. The staff understand specific needs of patients & 1 & 2 & 3 & 4 & 5 \\
\hline
\end{tabular}

